BMJ Paediatrics Open

\title{
Hypotonic and isotonic intravenous maintenance fluids in hospitalised paediatric patients: a randomised controlled trial
}

Silvio Fabio Torres, ${ }^{\oplus 1,2}$ Thomas Iolster, ${ }^{1}$ Eduardo Julio Schnitzler, ${ }^{1}$ Alejandro Javier Siaba Serrate, ${ }^{1}$ Nicolás A Sticco, ${ }^{1}$ Manuel Rocca Rivarola ${ }^{1}$

\section{ABSTRACT}

Objective To compare the changes in serum sodium and acid/base status in patients receiving hypotonic and isotonic solutions.

Design A randomised, controlled and double-blind clinical trial.

Setting Department of Paediatrics in a tertiary general hospital (Hospital Universitario Austral) in Buenos Aires, Argentina.

Patients Children between 29 days and 15 years of age who were hospitalised in the paediatric intensive care unit and general hospital between 12 January 2010 and 30 November 2016, and who required exclusively parenteral maintenance solutions for at least 24 hours.

Interventions A hypotonic solution with $77 \mathrm{mEq} / \mathrm{L}$ sodium chloride ( $0.45 \%$ in $5 \%$ dextrose) and isotonic solution with $150 \mathrm{mEq} / \mathrm{L}(0.9 \%$ in $5 \%$ dextrose) were infused for 48 hours and were labelled.

Main outcome measure The main outcome was to evaluate the incidence of hyponatraemia between patients treated with parenteral hydration with hypotonic or isotonic fluids. The secondary outcome was to estimate the incidence of metabolic acidosis induced by each of the solutions.

Results The 299 patients in the present study were randomised to groups that received the hypotonic solution ( $n=154)$ or isotonic solution $(n=145)$. The mean serum sodium concentration measurements at 12 hours were $136.3 \pm 3.9 \mathrm{mEq} / \mathrm{L}$ and $140.1 \pm 2.3 \mathrm{mEq} / \mathrm{L}$ in the hypotonic and isotonic groups, respectively, with a hyponatraemia incidence of $8.27 \%(n=12)$ and $18.8 \%$ $(n=29)(p<0.001)$. At 24 hours, 12.4\% $(n=18)$ of the isotonic group had developed hyponatraemia compared with $46.1 \%(n=71)$ of the hypotonic group $(p<0.001)$. The mean serum sodium concentration measurements were $134.4 \pm 5.6$ and $139.3 \pm 3.1$, respectively. No patient developed hypernatraemia (serum sodium concentrations $>150 \mathrm{mEq} / \mathrm{L}$ ) or other adverse outcomes. The relative risk in the hypotonic group was 3.7 (95\% $\mathrm{Cl} 2.3$ to 5.9), almost four times the risk of developing hyponatraemia than those who received isotonic fluids. There were also no significant differences between the groups with regard to the development of metabolic acidosis. Hypotonic solution, age $<12$ months and postoperative abdominal surgery were risk factors associated with hyponatraemia.
What is known about the subject?

There have been numerous publications that describe the development of hyponatraemia in children who receive hypotonic fluids.

- Previous studies have observed deaths and neurological disorders associated with hyponatraemia in hospitalised children.

What this study adds?

This is the first large study in Latin America evaluating the incidence of metabolic acidosis using hypotonic versus isotonic solutions.

- It also adds understanding about the risks of adverse effects using these solutions.

Conclusions The incidence of iatrogenic hyponatraemia was greater with the administration of hypotonic fluids compared with that of isotonic fluids. There were no significant differences in the incidence of metabolic acidosis between the groups.

\section{INTRODUCTION}

In the paediatric population, the administration of parenteral therapy to maintain homeostasis of sodium and water has always been of interest. Hyponatraemia, defined as a serum sodium level of $<135 \mathrm{mEq} / \mathrm{L}$, is a frequent disorder in hospitalised children. ${ }^{1}$ In this age group, decreases in serum chloride and sodium concentrations of $5-6 \mathrm{mEq} / \mathrm{L}$ have been observed within the first 48 hours of hospitalisation when hypotonic solutions were administered or when other sources of free water existed. ${ }^{12}$

Maintenance solutions must guarantee the supply of water and electrolytes in patients unable to take oral ingestion; however, there is not yet a universal consensus regarding the composition of these solutions in the 
paediatric population despite growing evidence against the use of intravenous hypotonic solutions as maintenance fluids in this population. ${ }^{2-5}$

A number of studies have assessed the incidence of hyponatraemia in children,${ }^{6-10}$ reporting that the administration of hypotonic solutions in children increases the risk of hyponatraemia in contrast to that for isotonic solutions. $^{2791112}$

The present study could be an important evidence in Latin America, where hypotonic solutions are still frequently used for hydration of paediatric patients despite studies that support the use of isotonic solutions. The differences in the risk of hyponatraemia in both solutions have never been compared in Latin America.

This study analysed the incidence of hyponatraemia between patients treated with parenteral hydration with hypotonic or isotonic fluids. Additionally, as recent studies ${ }^{13-15}$ suggest that the use of isotonic fluids with the same proportions of sodium and chloride concentrations can induce metabolic acidosis, we measured the blood $\mathrm{pH}$ of all enrolled patients to estimate the incidence of metabolic acidosis using each of the solutions.

\section{MATERIALS AND METHODS \\ Design}

This is a randomised, controlled and double-blind clinical trial. The trial was registered in March 2009 on RENIS (Registro Nacional Argentino de Investigaciones en Salud; https://sisa.msal.gov.ar).

\section{Patient and public involvement}

A member of the Institutional Evaluation Committee who belongs to the community as a representative of the patients participated in the design of the study. The following issues were considered: definition of the research questions, data confidence, data access, outcome and public dissemination of the results.

\section{Patients}

This study included children between 29 days and 15 years of age who had normal serum sodium concentrations on admission, were hospitalised in the Department of Pediatrics of the Hospital Universitario Austral (Pilar, Buenos Aires, Argentina) between 12 January 2010 and 30 November 2016, and required exclusively parenteral maintenance solutions for at least 24 hours. The exclusion criteria were patients with acute and chronic heart failure; immediate postoperative cardiac surgery; acute or chronic renal failure; nephritic or nephrotic syndromes; cirrhosis and/or immediate liver transplant status; history of syndrome of inappropriate secretion of antidiuretic hormone, bronchopulmonary dysplasia or pulmonary hypertension (diagnosed by echocardiography); prescription of diuretics, converting enzyme inhibitors and calcium channel blockers; and the presence of hyponatraemia prior to the administration of the solutions.
The exclusion criteria also included the following: children who did not undergo two determinations of serum sodium concentrations, those who had received an infusion of at least one dose of diuretics, the appearance of heart or kidney failure during the course of the study, interruption of fluid therapy by the attending physician, urinary osmolarity greater than $100 \mathrm{mOsm} / \mathrm{kg}$ and a weight change $>2 \%$ in the first 24 hours.

The presence of the following variables was recorded: sodium $(\mathrm{mEq} / \mathrm{L})$, mild hyponatraemia (sodium $(\mathrm{Na})$ $\leq 135 \mathrm{mEq} / \mathrm{L}$ ), moderate hyponatraemia $(\mathrm{Na} \leq 130$ $\mathrm{mEq} / \mathrm{L})$, hypernatraemia $(\mathrm{Na}>150 \mathrm{mEq} / \mathrm{L})$, blood $\mathrm{pH}$, metabolic acidosis ( $\mathrm{pH}<7.30)$, age (months), sex, death and baseline diagnosis (table 1).

Each of the patients included in this study had three sodium measurements on admission and at 12 and 24 hours. Additionally, we analysed blood $\mathrm{pH}$, electrolytes, urea and glucose on admission and at 12 and 24 hours in all patients.

\section{Intervention}

Hypotonic solution with $77 \mathrm{mEq} / \mathrm{L}$ sodium chloride $(0.45 \%$ in $5 \%$ dextrose) and isotonic solution with $150 \mathrm{mEq} / \mathrm{L}$ $(0.9 \%$ in $5 \%$ dextrose) were infused for 48 hours and were labelled. In both groups, the volume of liquids to be infused was calculated according to the Holliday-Segar formula. ${ }^{3}$ The solutions were administered by peripheral, central, implantable or semi-implantable venous catheters.

The hydration solutions were prepared and masked in the pharmacy by two pharmacy technicians coordinating the research. The solutions were made under laminar flow, complying with the standards of quality and biosecurity present in the clinical practice guidelines and procedures of the Austral Hospital. They were stored in individual closed bags until their delivery with the respective scrambling code number.

Per-protocol analysis was performed for both groups. The randomisation was performed by a sequence of random numbers generated on a computer (Microsoft Excel 2010) in blocks of four. The randomisation code was only known to the pharmacy coordinator and was hidden from all medical and nursing staff responsible for patient care.

The researchers who carried out the recruitment, processing and subsequent analysis of the data did not participate in the care and clinical monitoring of the patients.

\section{Statistical analysis}

A sample size was calculated based on the difference in proportions for categorical data. In order to detect a difference of at least $10 \%$ between the incidences of hyponatraemia in the groups, with a power of $90 \%$ and a level of significance of $5 \%$, a minimum of 50 patients per treatment group was required.

Continuous data were expressed as mean $\pm \mathrm{SD}$ or as median and IQR. According to the verification of the normality assumptions of the population, the samples were compared using Student's t-test or Wilcoxon test. 
Table 1 Baseline characteristics of both groups showing a balanced sample without significant differences between the groups

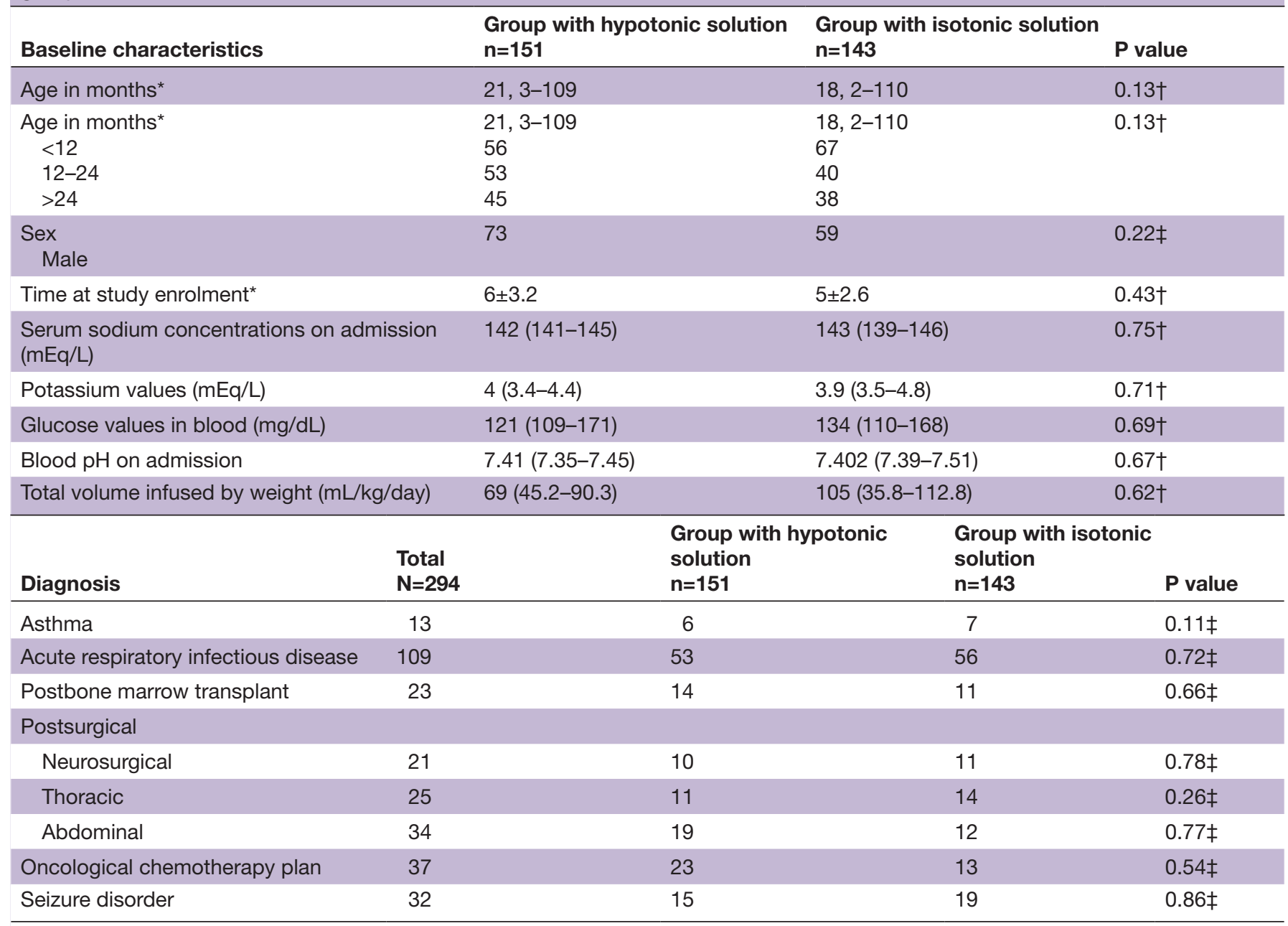

*Median, IQR (25-75).

†Wilcoxon test.

$\ddagger$ Pearson's $\chi^{2}$ test.

Categorical data were expressed as proportions and compared using the $\chi^{2}$ or Fisher's tests. A $p$ value $<0.05$ was considered statistically significant. Multivariable logistic regression was conducted to predict the incidence of hyponatraemia in each of the groups by studying the influence of the other variables.

Stata V.8.0 was used for statistical analyses.

\section{RESULTS}

According to the computerised records of the Austral University Hospital, the Department of Pediatrics had a total of 12200 admissions for hospitalisation between 1 December 2010 and 30 October 2016, including 2590 to the paediatric intensive and intermediate care units.

A total of 318 patients (figure 1) were eligible and randomised for the study, of whom 19 were excluded according to the pre-established criteria. Five did not undergo a second measurement for serum sodium concentrations, three had received at least one dose of diuretics, four had associated comorbidity, and the parents of the remaining seven refused to sign the informed consent.

Five patients were lost to follow-up, resulting in 151 and 143 patients in the hypotonic and isotonic solution groups, respectively. The median serum sodium concentration measurements at 12 hours were $136.3 \mathrm{mEq} / \mathrm{L}$ (IQR: 133-139) and $140.1 \mathrm{mEq} / \mathrm{L}$ (IQR: 138-142) in the hypotonic and isotonic groups, respectively. The incidence of mild hyponatraemia was $18.8 \%(\mathrm{n}=29)$ in the hypotonic group and $8.2 \%(n=12)$ in the isotonic group, with a statistically significant difference (table 2 ).

At 24 hours, the median serum sodium concentrations were $134.4 \mathrm{mEq} / \mathrm{L}$ (IQR: 128-139) and $139.3 \mathrm{mEq} / \mathrm{L}$ (IQR: 136-142) in the hypotonic and isotonic groups, respectively (table 2). The hypotonic group developed mild hyponatraemia in $46.1 \%(\mathrm{n}=71)$ compared with $12.4 \%(\mathrm{n}=18)$ of the isotonic group, and this difference was statistically significant.

There were only five patients with moderate hyponatraemia, and all of them belong to the hypotonic group. 


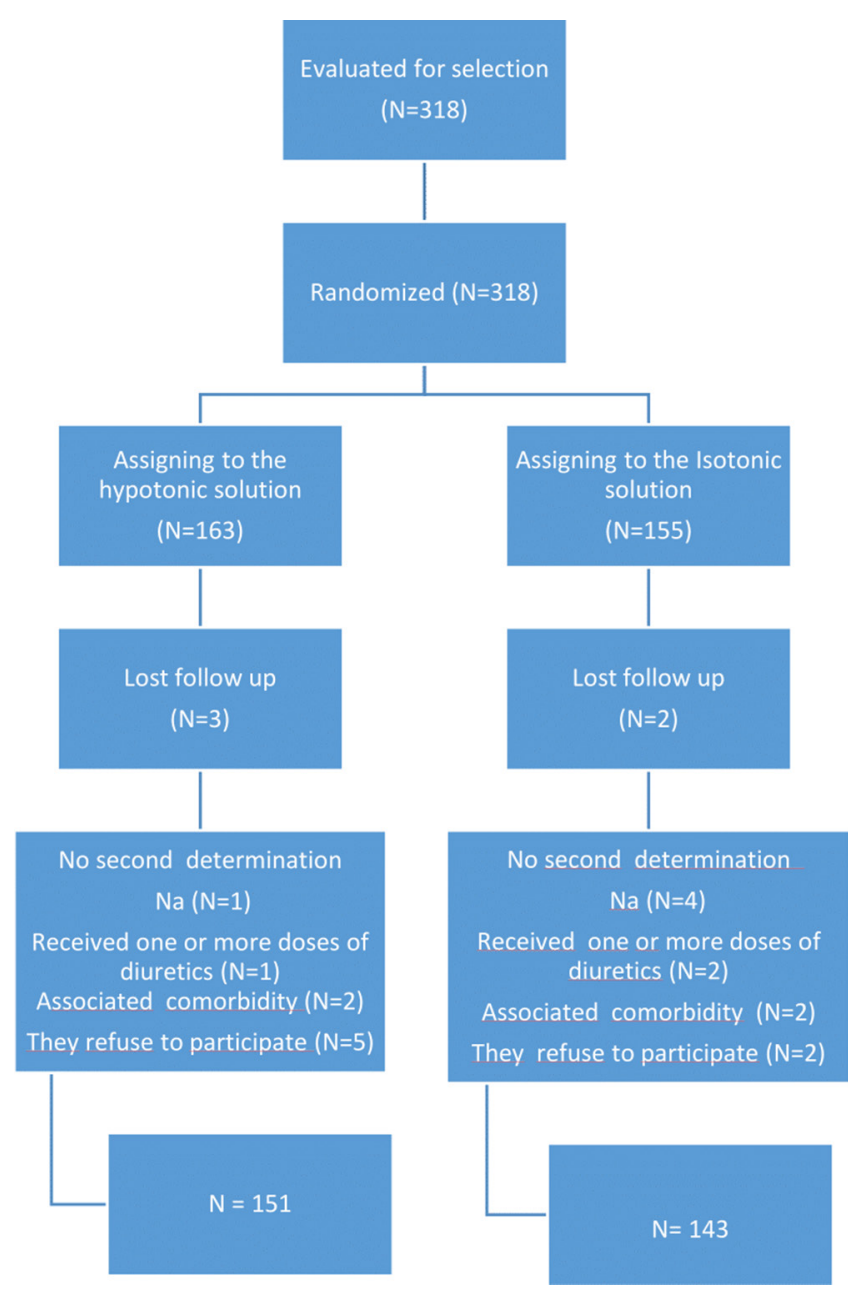

Figure 1 Flow chart of subject assignment and selection. $\mathrm{Na}$, sodium.

We did not find cases of hypernatraemia in any of the groups (serum sodium concentrations $>150 \mathrm{mEq} / \mathrm{L}$ ) or other adverse outcomes. At 12 and 24 hours we did not observe a statistically significant difference in the blood pH (table 2).

Comparison of the group that received hydration with the isotonic solutions in relation to the hypotonic solution group revealed a risk difference of -0.33 . The relative risk $(\mathrm{RR})$ of developing hyponatraemia in the hypotonic group was 3.7 (95\% CI 2.33 to 5.91); therefore, patients who received hypotonic fluids had almost four times the risk of developing hyponatraemia than those who received isotonic fluids.

There were also no significant differences between groups and 12 and 24 hours with regard to the development of metabolic acidosis (table 2). The proportions of patients with blood $\mathrm{pH}<7.30$ were $17.9 \%(\mathrm{n}=26)$ and $26.2 \%(n=38)$ in the isotonic group at 12 and 24 hours and $11.6 \%(\mathrm{n}=18)$ and $20.7 \%(\mathrm{n}=32)$ in the hypotonic group.

Although the restriction imposed by the inclusion and exclusion criteria could control for some confounding variables and effect modifiers, we improved on this aspect by performing multivariable logistic regression analysis.

Based on the particular behaviour of each of the variables in univariate analysis (table 3 ), the variables with statistical significance were selected for multivariable analysis. We observed that hypotonic solution (OR: 1.98, 95\% CI 1.69 to $4.91, \mathrm{p}=0.04$ ), age $<12$ months (OR: 1.07 , 95\% CI 1.05 to $1.08, \mathrm{p}=0.03$ ) and postoperative abdominal surgery (OR: 2.13, 95\% CI 1.02 to $3.03, \mathrm{p}=0.05$ ) were associated with hyponatraemia The performance of the multivariable analysis was tested by a receiver operating characteristic curve (figure 2).

\section{DISCUSSION}

In this study, the use of isotonic solutions reduces the development of iatrogenic hyponatraemia in

\begin{tabular}{|c|c|c|c|}
\hline & Hypotonic group & Isotonic group & $P$ value \\
\hline Patients with mild hyponatraemia $(\mathrm{Na}<135)$ at 12 hours & 29/154 (18.8\%) & $12 / 145(8.2 \%)$ & $<0.01^{*}$ \\
\hline Patients with mild hyponatraemia $(\mathrm{Na}<135)$ at 24 hours & $66 / 154(42.8 \%)$ & $18 / 145(12.4 \%)$ & $<0.01^{*}$ \\
\hline Patients with moderate hyponatraemia $(\mathrm{Na}<130)$ at 12 hours & $0 / 154$ & $0 / 145$ & \\
\hline Patients with moderate hyponatraemia $(\mathrm{Na}<130)$ at 24 hours & $5 / 154(3.2 \%)$ & $0 / 145$ & \\
\hline Patients with metabolic acidosis $(\mathrm{pH}<7.30)$ at 12 hours & $18 / 154(11.6 \%)$ & $26 / 145(17.9 \%)$ & $0.32^{*}$ \\
\hline Patients with metabolic acidosis $(\mathrm{pH}<7.30)$ at 24 hours & $32 / 154(20.7 \%)$ & $38 / 145(26.2 \%)$ & $0.71^{*}$ \\
\hline Sodium serum $(\mathrm{mEq} / \mathrm{L})$ at 12 hours $\dagger$ & $136.3(133-139)$ & $140.1(138-142)$ & $0.02 \ddagger$ \\
\hline Sodium serum $(\mathrm{mEq} / \mathrm{L})$ at 24 hours $\dagger$ & $134.4(128-139)$ & $139.3(136-142)$ & $0.03 \ddagger$ \\
\hline $\mathrm{pH}$ in blood at 12 hours $†$ & $7.36(7.31-7.42)$ & $7.34(7.27-7.40)$ & $0.18 \ddagger$ \\
\hline $\mathrm{pH}$ in blood at 24 hours $\dagger$ & $7.39(7.35-7.40)$ & $7.36(7.29-7.39)$ & $0.31 \neq$ \\
\hline Serum bicarbonate $(\mathrm{mmol} / \mathrm{L})$ at 12 hours $\dagger$ & $23(21-31)$ & $24(19-28)$ & $0.23 \ddagger$ \\
\hline Serum bicarbonate $(\mathrm{mmol} / \mathrm{L})$ at 24 hours $\dagger$ & $28(24-33)$ & $25(22-31)$ & $0.19 \ddagger$ \\
\hline
\end{tabular}

Categorical variables are expressed as percentages.

${ }^{*} \chi^{2}$ test.

†Median, IQR (25-75).

Wilcoxon test.

$\mathrm{Na}$, sodium. 
Table 3 Univariate analysis

\begin{tabular}{|c|c|c|c|}
\hline \multirow{3}{*}{$\begin{array}{l}\text { Univariate analysis } \\
\text { Variables } \\
\end{array}$} & \multicolumn{2}{|c|}{ Hyponatraemia } & \multirow{3}{*}{$\begin{array}{l}\text { P value } \\
<0.01\end{array}$} \\
\hline & \multicolumn{2}{|c|}{ OR, 95\% Cl } & \\
\hline & 3.24 & 2.7 to 5.3 & \\
\hline Age $12-24$ months & 2.13 & 0.8 to 9.3 & 0.75 \\
\hline Age $>24$ months & 1.24 & 0.4 to 5.9 & 0.46 \\
\hline Male & 1.75 & 1.0 to 2.6 & 0.02 \\
\hline After thorax surgery & 0.52 & 0.3 to 1.7 & 0.07 \\
\hline After neurosurgery & 2.01 & 0.7 to 4.7 & 0.06 \\
\hline After abdominal surgery & 2.03 & 1.9 to 4.5 & 0.01 \\
\hline Convulsive syndrome & 1.47 & 0.8 to 4.7 & 0.07 \\
\hline $\begin{array}{l}\text { Acute infectious respiratory } \\
\text { disease }\end{array}$ & 2.34 & 1.1 to 5.2 & 0.05 \\
\hline
\end{tabular}

\begin{tabular}{llll} 
Asthma & 0.56 & 0.3 to 12.1 & 0.78 \\
\hline $\begin{array}{l}\text { Treatment with chemotherapy } \\
\text { (oncological and transplanted } \\
\text { patients of bone marrow) }\end{array}$ & 0.65 & 0.2 to 1.8 & 0.06 \\
\hline
\end{tabular}

hospitalised paediatric patients receiving exclusive parenteral hydration during 24 hours compared with children who received hypotonic fluids. The RR for developing hyponatraemia was 3.17 , and this is similar to other studies, including a meta-analysis ${ }^{7}$ involving almost 1000 children where hypotonic fluids were associated with an RR of 2.37 for developing mild hyponatraemia and 6.2 for developing moderate hyponatraemia.

There has been much discussion about the routine use of hypotonic fluids and the risk of hyponatraemia in hospitalised children. ${ }^{16-18}$ Although numerous clinical studies have shown differences between children treated with both solutions, they do not always reach statistical significance, perhaps due to the sample size. ${ }^{17-19}$ However, McNab et al have recently produced

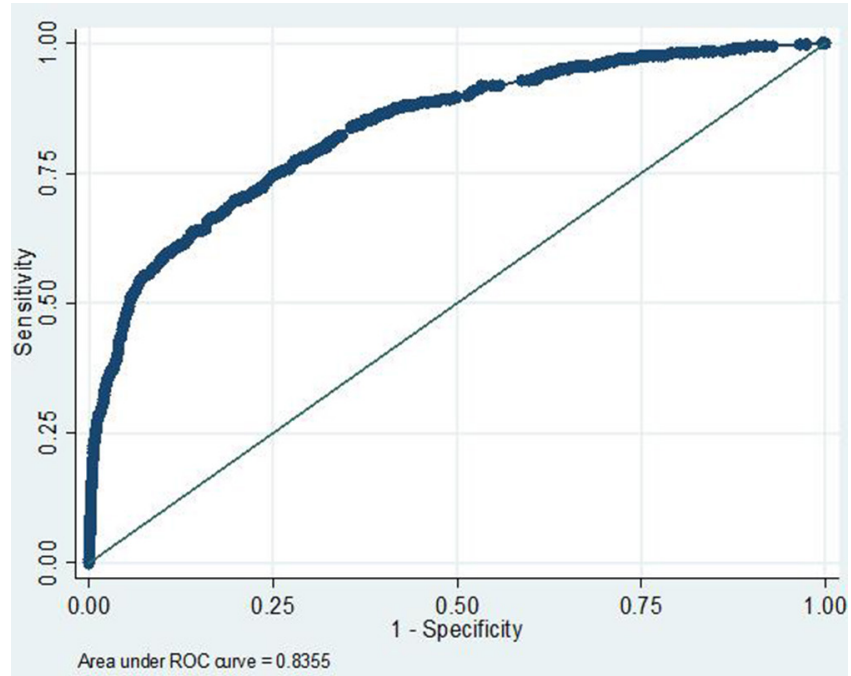

Figure 2 Area under the receiver operating characteristic (ROC) curve, 0.83 (95\% Cl 0.819 to 0.848). categorical evidence showing prevention of hyponatraemia with the use of isotonic fluids. ${ }^{20}$

The multivariable analysis revealed that age $<12$ months and postsurgical abdominal surgery were significantly associated with the development of hyponatraemia.

Young children present difficulties in maintaining a hypertonic renal medulla, which could explain the association of age $<12$ months with hyponatraemia. Among abdominal postoperative patients, excess interstitial fluid immediately postintervention as well as the presence of colostomies (with possible sodium loss) in some of these children could justify the association. However, both situations had an increased incidence of hyponatraemia, regardless of the infused solution.

Moritz and Ayus ${ }^{1921}$ reported an incidence of death in patients with iatrogenic hyponatraemia of $8.4 \%(95 \%$ CI 1.85 to 15.01 ) and that 1 in 12 patients who acquired in-hospital hyponatraemia could die, thus showing the potential for severe consequences of the administration of hypotonic solutions. In our study, no patients died, probably due to the fact that they were mainly clinically stable patients, including those admitted to the intensive care unit who had a low risk of expected mortality, with a paediatric mortality index classification of 2 on admission. We did not observe neurological symptoms in either group based on the serum sodium concentration values, as might occur in cases of abrupt fluctuations of serum sodium or hyponatraemia with values lower than 130-125 mEq/L.

Several studies have suggested that the main factor associated with iatrogenic hyponatraemia is the continuous intravenous infusion of hypotonic solutions for more than 6 hours. ${ }^{181921}$ Holliday et al reported that maintaining isotonic fluids for $6-12$ hours in postsurgical patients restored blood volume and reduced $\mathrm{ADH}$ (Antidiuretic hormone) secretion; however, the authors recommend changing to hypotonic solutions after 12 hours due to the potential risk of hypernatraemia. ${ }^{18}$ The possibility of inducing hypernatraemia with isotonic fluids is very low in contrast to the high risk of generating hyponatraemia by maintaining hypotonic fluids. Numerous studies have reported a protective effect against hyponatraemia with the infusion of isotonic solutions from the time of admission and for more than 12 hours. ${ }^{17} 1921-23$ Our study focused only on patients who received parenteral support exclusively. We did not perform evaluations after 24 hours of treatment when children are frequently fed via the enteral route, and the normal compensatory mechanisms are expected to normalise the serum sodium concentrations.

The American Academy of Pediatrics Clinical Practice Guideline: Maintenance Intravenous Fluids in Children, recently published, recommends that patients 28 days-18 years of age requiring maintenance intravenous fluids should receive isotonic solutions with appropriate potassium chloride and dextrose because 
they significantly decrease the risk of developing hyponatraemia. In this paper the authors comment on the importance of analysing whether the use of $0.9 \%$ saline fluids for maintenance can increase the incidence of metabolic acidosis. ${ }^{24}$

One of the contributions of our study was its analysis of the risk of developing hyperchloraemic metabolic acidosis after the infusion of isotonic solutions with the same concentrations of chloride and sodium. This adverse collateral effect has been reported in different series $^{131822}$ and clinical trials. ${ }^{141523}$ In our study, we did not observe a statistically significant difference in the incidence of metabolic acidosis.

Finally, in our study we excluded children with renal or cardiac comorbidities; however, the potential for the development of hyponatraemia following the administration of hypotonic solutions should also be considered in these patients with difficulties in the excretion of free water. This could be a consideration for future studies.

\section{CONCLUSIONS}

The incidence of iatrogenic hyponatraemia was greater with the administration of hypotonic fluids compared with isotonic fluids. There were no significant differences in the incidence of metabolic acidosis between the groups.

Acknowledgements We are grateful to Dr Juan Carlos Ayus for conception of this manuscript.

Funding The authors have not declared a specific grant for this research from any funding agency in the public, commercial or not-for-profit sectors.

Competing interests None declared.

Patient consent for publication Obtained.

Ethics approval The study was approved by the Institutional Evaluation Committee (IEC) of the Austral University Hospital (HUA). The parents and/or guardians of the children authorised their participation in the study after having read and understood the informed consent prepared under the rules of the IEC.

Provenance and peer review Not commissioned; externally peer reviewed.

Data availability statement Data are available in a public, open access repository.

Open access This is an open access article distributed in accordance with the Creative Commons Attribution Non Commercial (CC BY-NC 4.0) license, which permits others to distribute, remix, adapt, build upon this work non-commercially, and license their derivative works on different terms, provided the original work is properly cited, appropriate credit is given, any changes made indicated, and the use is non-commercial. See: http://creativecommons.org/licenses/by-nc/4.0/.

\section{REFERENCES}

1. Behrman RE, Kliegman RM, Jenson HB. Nelson. Tratado de Pediatría . 17 a ed. Madrid: Elsevier, 2004: 45. 199.

2. Hoorn EJ, Geary D, Robb M, et al. Acute hyponatremia related to intravenous fluid administration in hospitalized children: an observational study. Pediatrics 2004;113:1279-84.

3. Holliday MA, Segar WE. The maintenance need for water in parenteral fluid therapy. Pediatrics 1957;19:823-32.

4. Moritz ML, Ayus JC. Prevention of hospital-acquired hyponatremia: a case for using isotonic saline. Pediatrics 2003;111:227-30.

5. Adrogué H, Madias N. Hyponatremia. N Engl J Med 2007:1581-9.

6. Shafiee MAS, Bohn D, Hoorn EJ, et al. How to select optimal maintenance intravenous fluid therapy. QJM 2003;96:601-10.

7. Foster BA, Tom D, Hill V. Hypotonic versus isotonic fluids in hospitalized children: a systematic review and meta-analysis. The Journal of Pediatrics 2014;165:163-9.

8. Judd BA, Haycock GB, Dalton RN, et al. Antidiuretic hormone following surgery in children. Acta Paediatr Scand 1990;79:461-6.

9. Jenkins J, Taylor B. Prevention of hyponatremia. Arch Dis Child 2004;89.

10. Halberthal M, Halperin ML, Bohn D. Lesson of the week: acute hyponatraemia in children admitted to hospital: retrospective analysis of factors contributing to its development and resolution. BMJ 2001;322:780-2.

11. Hoorn E, Geary D, Robb M, et al. Acute hyponatremia related to intravenous fluid administration in hospitalized children: an observational study. Pediatrics 2007:1279-84.

12. Moritz ML, Ayus JC. The pathophysiology and treatment of hyponatraemic encephalopathy: an update. Nephrology Dialysis Transplantation 2003;18:2486-91.

13. Corey HE. Stewart and beyond: new models of acid-base balance. Kidney International 2003;64:777-87.

14. Scheingraber S, Rehm M, Sehmisch C, et al. Rapid saline infusion produces hyperchloremic acidosis in patients undergoing gynecologic surgery. Anesthesiology 1999;90:1265-70.

15. McFARLANE C, Lee A. A comparison of Plasmalyte 148 and $0.9 \%$ saline for intra-operative fluid replacement. Anaesthesia 1994;49:779-81.

16. Choong Ket al. Hypotonic versus isotonic saline in hospitalised children: a systematic review. Archives of Disease in Childhood 2006;91:828-35.

17. Montañana PA, Modesto i Alapont V, Ocón AP, et al. The use of isotonic fluid as maintenance therapy prevents iatrogenic hyponatremia in pediatrics: a randomized, controlled open study. Pediatr Crit Care Med 2008;9:589-97.

18. Holliday MA, Friedman AL, Segar WE, et al. Acute hospital-induced hyponatremia in children: a physiologic approach. The Journal of Pediatrics 2004;145:584-7.

19. Moritz ML, Ayus JC. Intravenous fluid management for the acutely ill child. Current Opinion in Pediatrics 2011;23:186-93.

20. McNab S, Duke T, South M, et al. $140 \mathrm{mmol} / \mathrm{L}$ of sodium versus $77 \mathrm{mmol} / \mathrm{L}$ of sodium in maintenance intravenous fluid therapy for children in hospital (PIMS): a randomised controlled double-blind trial. The Lancet 2015;385:1190-7.

21. Moritz ML, Ayus JC. Maintenance intravenous fluids in acutely ill patients. N Engl J Med 2015;373:1350-60.

22. Shaw AD, Bagshaw SM, Goldstein SL, et al. Major complications, mortality, and resource utilization after open abdominal surgery: 0.9\% saline compared to Plasma-Lyte. Ann Surg 2012;255:821-9.

23. Yung M, Keeley S. Randomised controlled trial of intravenous maintenance fluids. J Paediatr Child Health 2009;45:9-14.

24. Feld LG, Neuspiel DR, Foster BA, et al. Clinical practice guideline: maintenance intravenous fluids in children. Pediatrics 2018;142:e20183083. 